\title{
Protective Effect of (-)-Epigallocatechin Gallate against Advanced Glycation Endproducts-Induced Injury in Neuronal Cells
}

\author{
Sun-joo LeE and Kwang-Won LeE* \\ Department of Food Science, College of Life Sciences \& Biotechnology; 1,5-ga, Anam-dong, Sungbuk-ku, Seoul 136-701, \\ Korea. Received March 6, 2007; accepted May 22, 2007
}

\begin{abstract}
Advanced glycation endproducts (AGEs) are believed to be secondary factors in the selective neuronal injury associated with several neurodegenerative disorders. In this study, we investigated the protective effects of (-)-epigallocatechin gallate (EGCG), a major monomer of green tea polyphenols, against AGEs-induced damage in neuron cells. The results showed that EGCG treatment protected against glyceraldehyde-derived AGE-induced neurotoxicity, which is associated with an increase in intracellular reactive oxygen species, as well as against decreases in intracellular catalase (CAT) and superoxide dismutase (SOD) activities. EGCG treatment also decreased malondialdehyde and carbonyl levels, and AGEs formation. Treatment with $10 \mu_{\mathrm{M}} \mathrm{EGCG}$ upregulated SOD and CAT levels, whereas glutathione peroxidase activity was reduced. Furthermore, $5 \mu \mathrm{M}$ EGCG was found to down-regulate the mRNA level of the AGE receptor (RAGE) in neuronal cells up to 2.5 fold, as determined by real time PCR. The results demonstrated that EGCG may exhibit protective effects against AGEs-induced injury in neuronal cells through its antioxidative properties, as well as by interfering with AGEs-RAGE interaction mediated pathways, suggesting a beneficial role for this tea catechin against neurodegenerative diseases.
\end{abstract}

Key words Alzheimer's disease; advanced glycation endproduct; (-)-epigallocatechin gallate; free radical; apoptosis

The amino groups of proteins, and particularly those on lysine residues, react nonenzymatically with reducing sugars, inducing a protein modification termed glycation. This glycation then leads to the formation of Amadori products via reversible Schiff-base adducts. Through subsequent oxidation and dehydration steps, a broad range of heterogeneous fluorescent and brown products form that are termed advanced glycation endproducts (AGEs). ${ }^{1)}$ There is increasing evidence that AGEs formation contributes to Alzheimer's disease (AD) as a secondary factor. AGEs are more than just markers of $\mathrm{AD}$ since they can also exert adverse biologic effects on tissues and cells. This includes the activation of intracellular signal transduction pathways via interaction with the main AGE receptor (RAGE), leading to the upregulation of cytokines and free radical production. ${ }^{2}$ Under normal conditions, reactive oxygen species (ROS) are efficiently neutralized by cellular antioxidant defense mechanisms. However, several conditions are known to disturb the balance between ROS production and cellular defense, resulting in cellular destruction and dysfunction.

Green tea is a popular beverage used world wide possessing many pharmacological effects such as antimutagenic, antiproliferative, and anticarcinogenic properties, as well as neuroprotective activities in models of degenerative disorders. ${ }^{3)}$ The beneficial effects ascribed to tea drinking are believed to rely on the pharmacological actions of catechins, especially (-)-epigallocatechin gallate the major catechin constituent, and the derivatives of catechin components. $\left.{ }^{4}\right)$ However, the effects of EGCG on AGEs-induced damage remain to be elucidated.

Using a human neuroblastoma cell line, we investigated the neuroprotective effects of EGCG against AGEs-induced injury involving signaling pathways of oxidative stress in neuron cells. Our data showed that EGCG contributed to the neuroprotective effects, partly through its abilities to inhibit the formation of AGEs and reduce oxidative stress.

\section{MATERIALS AND METHODS}

Materials EGCG (purity $\geq 98 \%$ ), thiazolylblue tetrazolium bromide (MTT), glyceraldehyde, glycoaldehyde, xanthine oxidase (XO), superoxide dismutase (SOD), glutathione reductase, and 2,4-dinitrophenylhydrazine were obtained from Sigma (St. Louis, MO, U.S.A.). Dulbecco's Modified Eagle Medium (DMEM), F-12 Ham Medium, and fetal bovine serum (FBS) were obtained from Gibco (Grand Island, NY, U.S.A.). $\mathrm{iQ}^{\mathrm{TM}}$ SYBR Green Supermix was obtained from Biorad (Watford, Herts, U.K.). TRIzol ${ }^{\circledR}$ Reagent, superscript reverse transcriptase, and $10 \mathrm{~mm}$ dNTP mix were obtained from Invitrogen (SanDeigo, CA, U.S.A.). An ApopNexin $^{\text {TM }}$ FITC Apoptosis detection kit was obtained from Chemicon (Temecula, CA, U.S.A.). All other chemicals used were of analytical grade. Equipment that was used included: a UV spectrophotometer (VS-530, Jasco, Japan), iCycler $\mathrm{iQ}^{\mathrm{TM}}$ Real-time PCR (Biorad, U.K.), Victor3 microplate reader (Perkin Elmer, U.S.A.), Centrifuge (VS-6000, Vision, Korea), Microcentrifuge (VS-15000CFN П, Vision, Korea), and a FACS Calibur ${ }^{\mathrm{TM}}$ Flow Cytometer (BD Biosciences, U.S.A.).

Preparation and Characterization of AGEs AGEs were produced according to the method of Vinson and Howard, ${ }^{5)}$ with slight modifications, by incubating $10 \mathrm{mg} / \mathrm{ml}$ of fatty acid free-bovine serum albumin (BSA) with $25 \mathrm{~mm}$ glyceraldehyde or glycoaldehyde and $1 \mathrm{~mm}$ diethylenetriaminepenta acetic acid (DTPA) in $0.1 \mathrm{M}$ phosphate buffered saline (PBS) $\left(\mathrm{pH} \mathrm{7.4)}\right.$ at $37^{\circ} \mathrm{C}$ for $7 \mathrm{~d}$. The same procedure, but without sugar, was used to prepare a non-glycated BSA. Unbound sugars were removed by dialysis in $10 \mathrm{~mm}$ PBS $(\mathrm{pH}$ 7.4) for $24 \mathrm{~h}$. The protein content was determined by Lowry assay, using BSA as the standard. The activity of general glycation was measured by general fluorescence at excitation $370 \mathrm{~nm} / \mathrm{emission} 440 \mathrm{~nm}$. The relative fluorescence of the general AGE increased 45-fold compared to the non-glycated BSA (data not shown). 
Cell Culture The human neuroblastoma cell line SHSY5Y was obtained from the American Type Culture Collection (ATCC, Manassas, VA, U.S.A.). The cells were grown in $100 \mathrm{~mm}$ petri dishes containing DMEM and Ham's Nutrient Mixture F-12 (1:1, v/v), and were supplemented with $10 \%$ FBS and $1 \%$ penicillin and streptomycin. The cells were grown in a humidified incubator at $37^{\circ} \mathrm{C}$ in a $5 \% \mathrm{CO}_{2}$ atmosphere, and were fed twice a week.

Reactive Oxygen Species ROS were detected by fluoroscence according to the method of Bass. ${ }^{6)}$ Briefly, SHSY5Y cells were preincubated with $2 \mu \mathrm{M} 2^{\prime}, 7^{\prime}$-dichlorofluorescin diacetate (DCFH-DA) for $30 \mathrm{~min}$ followed by $\mathrm{AGE}$ treatment for $24 \mathrm{~h}$. Fluorescence was obtained using Victor3 plate reader at excitation $485 \mathrm{~nm} / \mathrm{emission} 535 \mathrm{~nm}$.

Measurement of Carbonyl Levels Carbonyl levels were measured as reported previously. ${ }^{7)}$ Briefly, SH-SY5Y cells were washed twice with PBS, homogenized by $0.5 \%$ Triton $\mathrm{X}-100$, and centrifuged to remove debris. Then streptomycin solution was added to the supernatant $(1: 9, \mathrm{v} / \mathrm{v})$ for $15 \mathrm{~min}$. After centrifugation $(5000 \times \boldsymbol{g}, 10 \mathrm{~min})$, the supernatant was taken for assay. The proteins were pelleted by precipitation with $10 \%$ trichloroacetic acid followed by centrifugation $(5000 \times \boldsymbol{g}, 5 \mathrm{~min})$. The precipitate was resuspended in $0.5 \mathrm{ml}$ of $2 \mathrm{M} \mathrm{HCl}$, with or without $10 \mathrm{~mm}$ 2,4-dinitrophenylhydrazine, and stirred at $5 \mathrm{~min}$ intervals for $1 \mathrm{~h}$ at room temperature. The proteins were then pelleted again, followed by washing with ethanol/ethyl acetate $(1: 1, \mathrm{v} / \mathrm{v})$. The pellets were resuspended in $6 \mathrm{M}$ guanidine $/ 10 \mathrm{~mm}$ phosphate buffer/trifluoroacetic acid $(\mathrm{pH} 2.3)$, incubated at $37^{\circ} \mathrm{C}$ overnight, and centrifuged at $5000 \times \boldsymbol{g}$ for $3 \mathrm{~min}$. The absorbance of the supernatants was measured at $366 \mathrm{~nm}$ to assess carbonyl content, which was calculated using a molar absorption coefficient of $22.0 \times 10^{3} \mathrm{M}^{-1} \cdot \mathrm{cm}^{-1}$ for aliphatic hydrazones.

Intracellular Malondialdehyde Measurement Malondialdehyde (MDA), a lipid peroxidation product in the cells, was assayed using a thiobarbituric acid fluorometric method ${ }^{8}$ with excitation $515 \mathrm{~nm} /$ emission $552 \mathrm{~nm}$, and 1,1,3,3-tetramethoxypropane as the standard. Briefly, SH-SY5Y cells were harvested and homogenized by $0.5 \%$ Triton $\mathrm{X}-100$. The reaction mixture contained $300 \mu \mathrm{l}$ of TCA buffer $(0.25 \mathrm{~N} \mathrm{HCl} / 0.375 \%$ thiobarbituric acid $/ 15 \%$ trichloroacetic acid $/ 0.01 \%$ butyl hydroxytoluene), and was mixed with cell lysate. After centrifugation the supernatant was incubated in a shaking water bath at $85^{\circ} \mathrm{C}$ for $30 \mathrm{~min}$, an equal amount of $n$-butanol was added, and then fluorometric measurement performed. The protein concentration was determined by Lowry's method.

Antioxidant Enzyme Activity Assay The SH-SY5Y cells were washed twice with PBS and lysed in $200 \mu \mathrm{l}$ of lysis buffer [ $50 \mathrm{~mm}$ Tris- $\mathrm{HCl}(\mathrm{pH} 7.5) / 0.5 \%$ Triton $\mathrm{X}-100]$. The supernatants were obtained by centrifugation at $14000 \times \mathbf{g}$ at $4{ }^{\circ} \mathrm{C}$ for $10 \mathrm{~min}$, and antioxidant enzyme activity assays were performed on the resulting supernatants. The protein content was determined by Lowry's method. The superoxide dismutase (SOD) activity was determined by mixing the reaction mixture $[50 \mu \mathrm{M}$ xanthine $/ 0.1 \mathrm{~mm}$ EDTA/ $10 \mu \mathrm{M}$ cytochrome $\mathrm{C} / 50 \mathrm{~mm}$ potassium phosphate buffer (pH 7.8)] with the samples. ${ }^{9)}$ After adding 1 unit of SOD and 0.005 unit xanthine oxidase, the absorbance was read at $550 \mathrm{~nm}$ for $5 \mathrm{~min}$. The SOD activity was calculated as:
$\%$ inhibition $=\{$ absorbance $/ \mathrm{min}$ uninhibited - absorbance $/$ min inhibited $\} /\{$ absorbance/min uninhibited-absorbance/ min blank $\} \times 100$.

Catalase (CAT) activity was determined by adding $995 \mu \mathrm{l}$ of $30 \mathrm{mM} \mathrm{H}_{2} \mathrm{O}_{2}$ to $5 \mu \mathrm{l}$ of cell lysate. ${ }^{10)}$ The disappearance of $\mathrm{H}_{2} \mathrm{O}_{2}$ was monitored at $240 \mathrm{~nm}$. The catalase activity was calculated as: concentration $=($ absorbance - control $) /(43.6$ $\left.\mathrm{M}^{-1} \mathrm{~cm}^{-1}\right) \times$ path length $(1 \mathrm{~cm})$.

Glutathione peroxidase (GPx) activity was determined by adding reaction mixture $[0.1 \mathrm{M}$ phosphate buffer $(\mathrm{pH}$ 7.0) $/ 1 \mathrm{~mm}$ EDTA/ $10 \mathrm{~mm}$ glutathione/ $1 \mathrm{~mm} \mathrm{NaN}_{3} / 1$ unit of glutathione reductase $/ 1.5 \mathrm{~mm}$ NADPH] to cell lysate. ${ }^{11)}$ After a $10 \mathrm{~min}$ incubation at $37^{\circ} \mathrm{C}, 1 \mathrm{mM} \mathrm{H}_{2} \mathrm{O}_{2}$ was added to each sample. GPx activity was measured as the rate of NADPH oxidation at $340 \mathrm{~nm}$.

Quantitative Real Time Polymerase Chain Reaction (PCR) The total RNA was extracted from the cells using TRIzol ${ }^{\circledR}$ reagent according to the manufacturer's instructions. The total RNA ( $3 \mu \mathrm{g}$ ) was converted to cDNA by reverse transcriptase using a SuperScript ${ }^{\mathrm{TM}}$ II Reverse Transcriptase kit per manufacturer's instructions. Quantitative PCR of the cDNA samples was performed with a iCycler $\mathrm{iQ}^{\mathrm{TM}}$ RealTime Detection System. PCR was conducted using the primer for RAGE (Genebank No. AB036432) forward 5' AGCCCTCTCCTCAAATCCACT-3', reverse 5'-ACTACTCTCGCCTGCCTCAG-3'; and the primer for GAPDH (Genebank No. DQ894744) forward 5'-AGGTCGGCGTCAACGGATTTGG-3', reverse 5'-ACAGTCTTCTGGGTGGCAGTGATG-3'. Then $1 \mu \mathrm{l}$ of cDNA template was amplified in a mixture of $12.5 \mu \mathrm{l}$ of iQ SYBR Green Supermix, primer, and sterile water in a final volume of $25 \mu \mathrm{l}$. For all experiments, the negative controls used water instead of cDNA for the PCR reaction. The data were normalized by subtracting the difference of the threshold cycle $(\mathrm{Ct})$ values between the target gene of interest and the GAPDH housekeeping gene.

Apoptosis Assay Apoptosis was measured according to the manufacturer's instructions (Chemicaon, Temecular, CA, U.S.A.). Briefly, SH-SY5Y cells were collected by tripsinEDTA, washed with PBS, resuspended in $100 \mu \mathrm{l}$ of binding buffer [140 mm NaCl/10 mm HEPES (pH 7.4)/25 mm $\mathrm{CaCl}_{2}$ ], and stained with $3 \mu \mathrm{l}$ of fluorescein isothiocyanate-labeled Annexin-V (Annexin V-FITC) and $2 \mu \mathrm{l}$ of propidium iodide (PI). After $15 \mathrm{~min}$ of incubation, the cells were immediately analyzed by flow cytometry. For each analysis, 10000 cells were recorded.

Statistics The statistical significance of the differences was determined using unpaired Student's $t$-tests. Differences with $p$-values $<0.05$ were considered statistically significant. All graphs represent the mean \pm standard deviation (S.D.) for three separete experiments.

\section{RESULTS}

Screening of AGE Inhibitors The effect of EGCG on AGE formation was determined after incubating the reaction mixture with EGCG for 1 week. As shown in Table 1, EGCG significantly inhibited AGE formation up to $82.7 \%$ at a concentration of $50 \mu \mathrm{M}$, and caused $48 \%$ inhibition at a concentration of $10 \mu \mathrm{M}$. To compare the significance of the effect, the well-known AGEs inhibitor aminoguanidine (AG) was 
Table 1. Effects of EGCG on AGE Formation and Intracellular ROS

\begin{tabular}{lccc}
\hline \hline \multicolumn{1}{c}{ Material } & Concentration & Inhibition (\%) & $\begin{array}{c}\text { Relative DCF } \\
\text { fluorescence (\%) }\end{array}$ \\
\hline Glycation (-) & & $100 \pm 0.21$ & $100 \pm 0.90$ \\
Glycation (+) & & $0 \pm 1.7$ & $136 \pm 13$ \\
Epigallocatechin & $10 \mu \mathrm{M}$ & $47.8 \pm 1.5^{*}$ & $122 \pm 2.2$ \\
gallate & $25 \mu \mathrm{M}$ & $72.6 \pm 2.6^{*}$ & $110 \pm 2.6^{*}$ \\
Aminoguanidine & $50 \mu \mathrm{M}$ & $82.7 \pm 0.45^{*}$ & $102 \pm 2.8^{*}$ \\
& $5 \mathrm{mM}$ & $73.8 \pm 2.4^{*}$ & - \\
& $10 \mathrm{mM}$ & $80.7 \pm 0.80^{*}$ & - \\
\hline
\end{tabular}

a) Calculation $=\{$ sample $-\mathrm{gly}(-)\} /\{\mathrm{gly}(-)-\mathrm{gly}(+)\} \times 100$. b) The values obtained with the non-glycated control are considered $100 \%$. Data are the mean $(n=3) \pm$ S.D. $(* p<0.01)$.

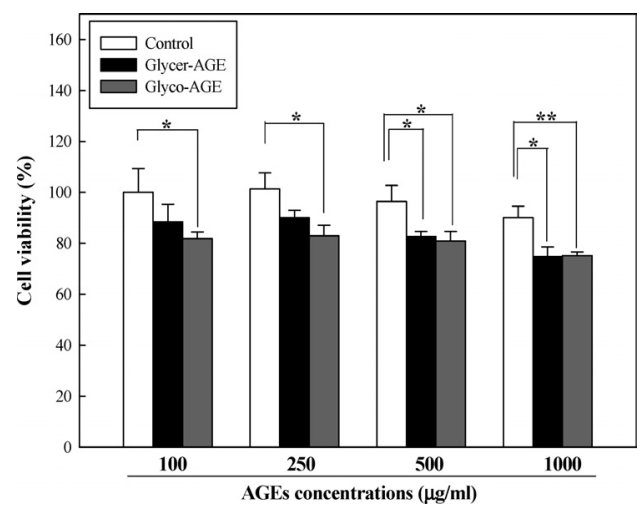

Fig. 1. Cytotoxicity of AGEs in SH-SY5Y Cells

SH-SY5Y cells grown to confluence were incubated with AGEs or a non-glycated control at concentrations of $100,250,500$, and $1000 \mu \mathrm{g} / \mathrm{ml}$. After incubation for $24 \mathrm{~h}$, viable cells were quantified by MTT assay. Data are the mean $(n=3) \pm$ S.D. $(* * p<0.01$, $* p<0.05$ ).

used. EGCG was able to express a similar inhibition effect with $25 \mathrm{~mm} A G$ at the $50 \mu \mathrm{M}$ concentration.

Effects of AGEs on Cell Viability In this study, to determine the cytotoxic effects of glyceraldehyde-induced AGE (glycer-AGE) and glycolaldehyde-induced AGE (glycoAGE) at various concentrations, we carried out MTT assays, a quantitative method to assess cell viability. As shown in Fig. 1, glycer-AGE and glyco-AGE both induced cell death in dose dependent manners. At a concentration above $10 \mu \mathrm{M}$, EGCG seemed to express a cytotoxic effect itself (data not shown). Due to these results, further assays were performed with glycer-AGE at a $500 \mu \mathrm{g} / \mathrm{ml}$ concentration, showing an $80 \%$ cell viability compared to the non-glycated control to induce a mild injury within the neuron cells, with EGCG (5, $10 \mu \mathrm{M})$ or without.

Effect of EGCG against Oxidative Stress Induced by AGEs As shown in Table 1, 50 $\mu \mathrm{M}$ EGCG was found to completely inhibit AGEs-induced ROS, although this concentration would be toxic within the cells. The $10 \mu \mathrm{M}$ EGCG was also able to decrease intracellular ROS $14 \%$ compared to the control.

When treated with glycer-AGE $(500 \mu \mathrm{g} / \mathrm{ml})$, carbonyl levels increased five-fold compared to treatments with the nonglycated control, as shown in Fig. 2. EGCG was able to attenuate carbonyl levels at both concentrations $(5,10 \mu \mathrm{M})$ up to $28.6 \%$, although there was no significant difference between these two groups. Next, we investigated whether EGCG could attenuate the AGE-induced lipid peroxidation
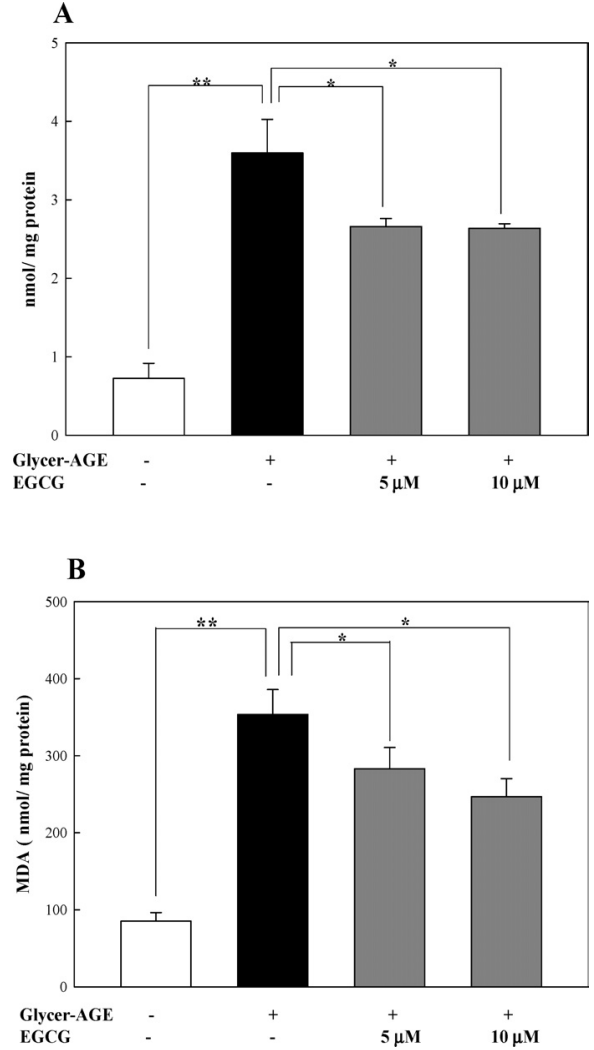

Fig. 2. Effects of EGCG on Protein Carbonyl Content and Malondialdehyde Levels in SH-SY5Y Cells

Carbonyl contents and MDA levels were determined in the SH-SY5Y cells after incubation with glycer-AGE $(500 \mu \mathrm{g} / \mathrm{ml})$ for $24 \mathrm{~h}$ with or without EGCG $(5,10 \mu \mathrm{M})$. Results are presented as nmol carbonyls/mg protein (A) and nmol MDA/mg protein (B). Data are the mean $(n=3) \pm$ S.D. $(* * p<0.01, * p<0.05)$.

product MDA. As shown in Fig. 2, glycer-AGE $(500 \mu \mathrm{g} / \mathrm{ml})$ leads to the production of thiobarbituric acid-reactive substances (TBARS) with a four-fold increase compared to the non-glycated control. The 5 and $10 \mu \mathrm{M}$ EGCG concentrations were able to reduce TBARS production induced by glycerAGE by approximately 20 and $30 \%$, respectively.

Since the $10 \mu \mathrm{M}$ EGCG concentration did not significantly reduce AGEs-induced ROS by direct scavenging, the intracellular level of antioxidant enzymes was considered as an alternative factor for the depletion of ROS. The activities of the antioxidant enzymes are shown in Fig. 3. Here there was a significant decrease in CAT activity between the glycerAGE $(500 \mu \mathrm{g} / \mathrm{ml})$ group and the non-glycated control by approximately 2.4 -fold. The 5 and $10 \mu \mathrm{M}$ concentrations of EGCG increased CAT activity approximately to the control level, respectively. The SOD activity showed a similar result by decreasing $36 \%$ when treated with glycer-AGE (500 $\mu \mathrm{g} / \mathrm{ml}$ ) compared to the non-glycated control. The 5 and 10 $\mu_{\mathrm{M}}$ EGCG were able to increase SOD activities up to $20 \%$ and $31 \%$, respectively. Conversely, when treated with glycerAGE, GPx activity increased up to $13 \%$ compared to the non-glycated control. EGCG at $10 \mu \mathrm{M}$ concentrations was able to significantly decrease GPx activity by $8.5 \%$, to the control level.

Effect of EGCG on AGEs-Induced RAGE To determine the effect of EGCG on RAGE gene expression, the RNA isolated from cells was analyzed by a iCycler Real-time PCR. As shown in Fig. 4, the $10 \mu \mathrm{M}$ EGCG down-regulated 

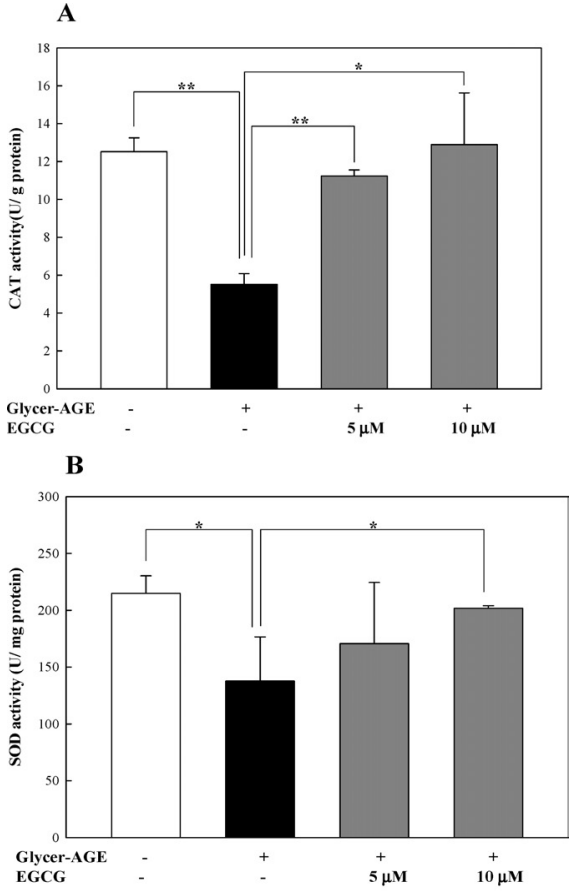

C

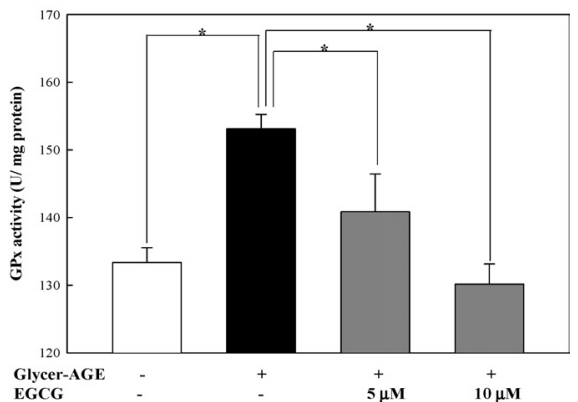

Fig. 3. Effects of EGCG against AGEs on Cellular CAT, SOD, and GPx Levels in SH-SY5Y Cells

SH-SY5Y cells treated with or without EGCG $(5,10 \mu \mathrm{M})$ were examined for cellular CAT, SOD, and GPx levels induced by glycer-AGE $(500 \mu \mathrm{g} / \mathrm{ml})$ for $24 \mathrm{~h}$. CAT levels (A) are expressed as unit/g proteins, while SOD (B) and GPx levels (C) are expressed as unit/mg proteins. Data are the mean $(n=3) \pm$ S.D. $(* * p<0.01, * p<0.05)$

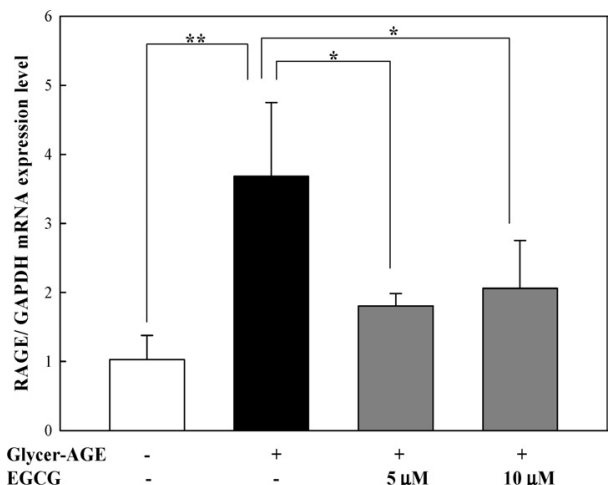

Fig. 4. Effect of EGCG on RAGE mRNA Levels

SH-SY5Y cells were treated with glycer-AGE $(500 \mu \mathrm{g} / \mathrm{ml})$ for $24 \mathrm{~h}$ with EGCG treatment $(5,10 \mu \mathrm{M})$ or without. RAGE expression levels are given. Data are the mean $(n=3) \pm$ S.D. $(* * p<0.01, * p<0.05)$.

RAGE mRNA levels up to $50 \%$.

Effect of EGCG on AGEs-Induced Apoptosis Next, we investigated whether EGCG could prevent AGEs-induced

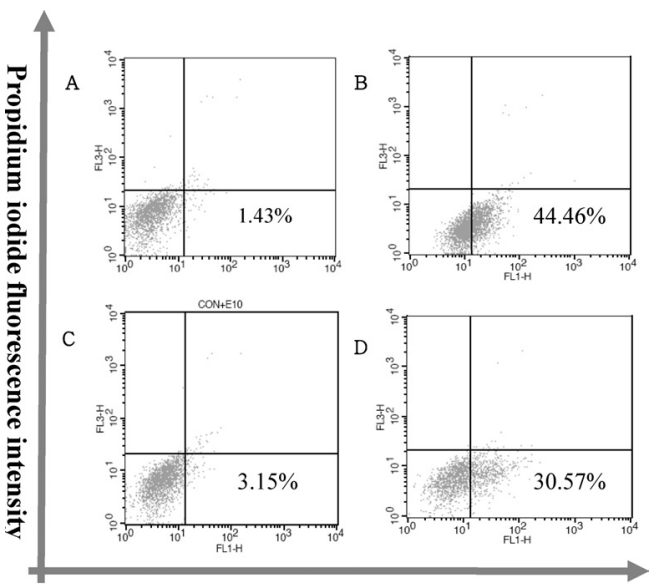

Annexin V fluorescence intensity

Fig. 5. Effect of EGCG on Cell Apoptosis

SH-SY5Y cells were preincubated with EGCG for $30 \mathrm{~min}$ and further incubated with glycer-AGE. The non-glycated contol (A), glycer-AGE $(1000 \mu \mathrm{g} / \mathrm{ml})(\mathrm{B})$, non-glycated control with EGCG $(10 \mu \mathrm{M})(\mathrm{C})$, and glycer-AGE $(1000 \mu \mathrm{g} / \mathrm{ml})$ with EGCG $(10 \mu \mathrm{M})$ (D) were incubated for $24 \mathrm{~h}$. Annexin fluorescence intensity was determined by flow cytometric analysis (FACS). 10000 cell counts were determined for each sample and $50 \%$ are shown in each dot plot.

apoptotic cell death in the SH-SY5Y cells. Apoptosis was characterized by Annexin $\mathrm{V}$ and the PI double-staining system; Annexin $\mathrm{V}^{+} / \mathrm{PI}^{-}$were used for measuring apoptosis, and Annexin $\mathrm{V}^{+} / \mathrm{PI}^{+}$for measuring necrosis. After $24 \mathrm{~h}$ of incubation with glycer-AGE $(1000 \mu \mathrm{g} / \mathrm{ml})$, the percentage of apoptotic cells increased approximately $45 \%$ compared to the non-glycated control (Fig. 5). Compared with glycer-AGE treatment only, pre-incubation with $10 \mu \mathrm{M}$ EGCG for $30 \mathrm{~min}$ followed by glycer-AGE treatment reduced apoptotic cell death by $10 \%$.

\section{DISCUSSION}

Accumulating evidence indicates that AGE formation and oxidative stress are important pathways leading to neuronal cell death in $\mathrm{AD}^{2)}$ Carbonyl stress, demonstrated by AGEs in tissue, also increases in AD. ${ }^{12)}$ In this study, we investigated the effect of EGCG on AGEs-induced injury in neuronal cells. The human SH-SY5Y neuroblastoma cell line was chosen because it has been widely used to investigate neurotoxic compounds, and constitutively expresses RAGE in amounts comparable with other cell lines. ${ }^{13)}$ Although the in vitro preparation of AGEs has not been established, a recent study showed that extensively-modified, unphysiological AGEs formed under in vitro conditions, may exert the same biological effects as AGE-rich serum fractions obtained from diabetic patients. ${ }^{14)}$ It has been confirmed that glycer-AGE and glyco-AGE show strong neurotoxicity on primary cultured rat cortical neurons. ${ }^{15)}$ In vitro, the neurotoxicity of these AGEs is stronger than that of glucose-AGE and $N$-(carboxymethyl)-lysine (CML), which has been studied extensively. In a recent immunohistochemical study, most of the neurons in $\mathrm{AD}$ brain tissues showed immunoreaction with glycer-AGE rather than glycol-AGE, which was presented mainly in the cytosol of neurons of the hippocampus and para-hippocampal gyrus. ${ }^{16)}$ Although both aldehyde-derived AGEs were able to express neurotoxic effects, it is believed that glycol-AGE shows more significant cell death due to the 
fact that the smaller the aldehyde, the more reactive it is with free amino groups, thus forming more pathological AGEs. Therefore, glycer-AGE was used for the further assays of this study. Also, glycer-AGE is likely to play an important role in AD. ${ }^{17}$

Our results showed that EGCG, a potent neuroprotective agent, protected neuronal cells from AGEs-induced injury via its antioxidant activity and anti-glycation effects. Although the mechanism was not determined, EGCG was able to decrease the formation of AGEs (Table 1) as well as carbonyl stress (Fig. 2A). Also, EGCG treatment at a concentration of $10 \mu \mathrm{M}$ was capable of reducing AGEs-induced oxidative stress by up-regulating the antioxidant enzyme activities of SOD and CAT, rather than by the direct scavenging of intracellular ROS (Table 1, Fig. 3). We were not able to clarify, here, the molecular mechanism for ROS in SH-SY5Y cells. However, apocyanin, an inhibitor of NADPH oxidase, was able to prevent $60 \%$ of the AGEs-induced ROS generation in cells (data not shown), suggesting the involvement of NADPH oxidase. An increased content of carbonyl groups is an indicator of the oxidative modification of amino acids, including the glycation reaction, due to the fact that Amadori rearrangement products have carbonyl groups in their structures. Our findings suggest that EGCG was able to reduce AGEs-mediated carbonyl stress as well as the malondialdehyde level (Fig. 2). Abnormally high levels of free radicals and the simultaneous decline of antioxidant defense mechanisms can lead to the damages of cellular organelles and enzymes. Intracellular antioxidant enzymes such as SOD, CAT, and GPx prevent cells from free radical-mediated disturbances by scavenging ROS. Our results showed that in contrast to SOD and CAT, GPx activity, which was elevated by glycer-AGE was significantly reduced by EGCG, indicating that EGCG attenuated oxidative stress without altering glutathione status. Another explanation could be the role of post-translation enzyme modification induced by glycation. In a recent study using rats with streptozotocin-induced diabetes, there was an increase in CAT gene expression in contrast to a decrease in enzyme activity. This observation suggested the role of post-translation enzyme modification and altering of the enzyme's activity with the glycation process. ${ }^{18)}$ However, in this study direct evidence of antioxidant enzyme modification by glycation was not determined. In addition, there is increasing evidence that AGEs are active participants in oxidative damage through their action as ligands for specific AGE receptors such as RAGE. RAGE is a multi-ligand member of the immunoglobulin superfamily of cell surface molecules known to activate NF- $\kappa \mathrm{B}$ and produce proinflammatory cytokines. ${ }^{19)}$ Therefore, RAGE expression was investigated in this study. The results implied that EGCG can prevent AGEs-induced injury by inhibiting RAGE activation.

Oxidative stress is closely linked to apoptosis in a variety of cell types. It can alter both signal transduction and genomic processes. Previously, when we used $500 \mu \mathrm{g} / \mathrm{ml}$ of glycer-AGE, no apoptotic cell death was determined (data not shown). In earlier experiments, AGEs-induced apoptosis was observed at the $500 \mu \mathrm{g} / \mathrm{ml}$ concentration when incubation was more than $2 \mathrm{~d}$ (data not shown). When SH-SY5Y cells were treated with glycer-AGE for more than $24 \mathrm{~h}$, the observed apoptosis was due to serum deprivation rather than the glycer-AGE. Therefore, we examined cell death induced with $1000 \mu \mathrm{g} / \mathrm{ml}$ glycer-AGE for $24 \mathrm{~h}$.

It has been reported that EGCG can penetrate the blood-

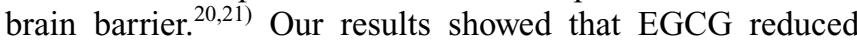
AGE-induced effects on neuronal cells. Thus, EGCG may be a prospective candidate to alleviate the involvement of AGE in the neurodegenerative process. Promising future treatments for neurodegenerative diseases and aging will depend on the availability of effective drugs that are brain permeable, iron-chelatable/radical scavenging, and neuroprotective, to prevent the progression of neurodegeneration. As far as we know, this is the first report to demonstrate the protective effects of EGCG against AGEs-induced injury in neuron cells. Additional studies will be needed to clarify EGCG's mechanism of apoptosis, as well as its potential therapeutic dose for in vivo models representing $\mathrm{AD}$.

Acknowledgements This work was supported by grant number R01-2002-000-00447-0 from the Basic Research Program of the Korea Science \& Engineering Foundation.

\section{REFERENCES}

1) De Arriba S. G., Loske C., Meiners I., Fleischer G., Lobisch M., Wessel K., Tritschler H., Schinzel R., Munch G., J. Cereb. Blood Flow Metab., 23, 1307-1313 (2003).

2) Munch G., Schinzel R., Loske C., Wong A., Durany N., Li J. J., Vlassara H., Smith M. A., Perry J., Riederer P., J. Neural. Transm., 105, 439-461 (1998).

3) Shuhong G., Erwan B., Baolu Z., Free Radic. Biol. Med., 39, 682695 (2005).

4) Mandel S., Weinreb O., Amit T., Youdim M. B., J. Neurochem., 88, 1555-1569 (2004).

5) Mahuren J. D., Coburn S. P., J. Nutr. Biochem., 1, 659-663 (1990)

6) Bass D. A., Parce J. W., Dechatelet L. R., Szejda P., Seeds M. C., Thomas M., J. Immunol., 130, 1910-1917 (1983).

7) Kaneto H., Fujii J., Myint T., Miyazawa N., Islam K. N., Kawasaki Y., Suzuki K., Nakamura M., Tatsumi H., Yamasaki Y., Taniguchi N., Biochem. J., 320, 855-863 (1996).

8) Hiroshi O., Nobuko O., Kunio Y., Anal. Biochem., 95, 351-358 (1979).

9) McCord J. M., Fridovich I., J. Biol. Chem., 244, 6049-6055 (1969).

10) Hou Y. Z., Zhao G. R., Yang J., Yuan Y. J., Zhu G. G., Hiltunen R. Life Sci., 75, 1775-1786 (2004).

11) Nanjo F., Goto K., Seto R., Suzuki M., Sakai M., Hara Y., Free Radic. Biol. Med., 21, 895-902 (1996).

12) Milenkovic J. G., Loske C., Munch G., J. Alzheimes Dis., 5, 25-30 (2003).

13) Sajithlal G., Huttunen H., Rauvala H., Munch G., J. Biol. Chem., 277, 6888-6897 (2002).

14) Yamgishi S., Amano S., Inagaki Y., Okamoto T., Koga K., Takeuchi M., Kidney Int., 63, 464-473 (2003).

15) Choei H., Sasaki N., Takeuchi M., Yoshida T., Ukai W., Yamagishi S., Kikuchi S., Saito T., Acta Neuropathol. (Berl), 108, 189-193 (2004).

16) Takeuchi M., Makita Z., Yanagisawa K., Kameda Y., Koike T., Mol. Med., 5, 393-405 (1999).

17) Glomb M. A., Monnier V. M., J. Biol. Chem., 270, 10017-10026 (1995).

18) Limaye P. V., Raghuram N., Sivakami S., Mol. Cell Biochem., 243, $147-152$ (2003)

19) Kang K. S., Kim H. Y., Yamabe N., Nagai R., Yokozawa T., Biol. Pharm. Bull., 29, 1678-1684 (2006).

20) Nakagawa K., Miyazawa T., J. Nutr. Sci. Vitaminol. (Tokyo), 43, 679 684 (1997).

21) Suganama M., Okabe S., Oniyama M., Tada Y., Ito H., Fujiki H., Carcinogenesis, 19, 1771-1776 (1998). 